\title{
ESTIMATIVA DE PARÂMETROS DE VARIAÇÃO GENÉTICA EM PROGÊNIES F 2 DE SOJA E GENITORES COM PRESENÇA E AUSÊNCIA DE LIPOXIGENASES
}

\author{
SANTOS, Elonha Rodrigues ${ }^{1}$ \\ SPEHAR, Carlos Roberto ${ }^{1}$ \\ CAPONE, Aristoteles ${ }^{1}$ \\ PEREIRA, Paulo Roberto ${ }^{1}$
}

\begin{abstract}
RESUMO: Objetivou-se com este trabalho estimar parâmetros genéticos (herdabilidade, coeficiente de variação genética e razão da variação genética e ambiental $\mathrm{CVg} / \mathrm{CVe}$ ), calcular as correlações fenotípicas e dispersão gráfica entre caracteres agronômicos em populações de soja formadas por cruzamento biparentais e seus genitores. A seleção foi concentrada em altura de plantas (AP) e de inserção de vagem (AIV), número de dias para maturação (NDM), número de vagens por planta (NVP) e rendimento de grãos (RG). O experimento foi conduzido no Distrito Federal, latitude $15^{\circ} 56^{\prime} \mathrm{S}$, longitude $47^{\circ} 56^{\prime} \mathrm{W}$ e altitude de $1.080 \mathrm{~m}$, em latossolo vermelho amarelo. A semeadura foi realizada em dezembro de 2013. O delineamento experimental foi o de blocos casualizados com quatro repetições. Os tratamentos foram constituídos por 22 genótipos (10 genitores e 12 cruzamentos). A parcela experimental foi constituída por uma linha com $2,5 \mathrm{~m}$ de comprimento, espaçada por $100 \mathrm{~cm}$. A análise mostrou ganhos para os caracteres estudados, medidos pela herdabilidade $\left(\mathrm{h}_{\mathrm{a}}{ }^{2}\right)$. A razão $\mathrm{CVg} / \mathrm{CVe}$ mostrou seleção favorável para NDM, AP, NVP e RG. A maior variabilidade genética (CVg) encontrada foi para NVP e RG. As correlações apresentaram magnitude média entre os caracteres NDM e AP, NDM e AIV, AP e AIV, AP e NVP, e NVP e RG. A seleção por NVP resulta em maior rendimento por planta. A dispersão gráfica permitiu observar os genótipos de forma isolada, indicando os cruzamentos mais promissores para serem avançados no procedimento de seleção.
\end{abstract}

Palavras-Chave: Cruzamento biparental. Herdabilidade. Correlação. CVg/CVe. Dispersão gráfica.

SUMMARY: Estimate of genetic parameters at early generations can increase the selection efficiency process in breeding programs. In view of this, the work aimed at estimating genetic parameters (heritability, genetic coefficient of variation and the ratio between genetic and environmental variation - $\mathrm{CVg} / \mathrm{CVe}$ ), calculate phenotypic correlations and graphic dispersion among agronomic characters in soybean $\mathrm{F}_{2}$ progenies from bi-parental crosses and genitors. The selection was concentrated in plant height $(\mathrm{PH})$ and first pod (FPH), number of days to maturity (NDM), number of pods per plant (NPP) and grain yield (GY). The experiment was conducted in the Federal District, 15 56'S and $47^{\circ} 56^{\prime} \mathrm{W}, 1,080 \mathrm{~m}$ altitude, in savannah red yellow latosol. Sowing was carried out in December 2013, using a complete randomized bloc design with four repetitions. The treatments were made by 22 genotypes (10 genitors and 12 crosses). The experimental unit consisted of a $2.5 \mathrm{~m}$ single row plot, spaced by $0.5 \mathrm{~m}$. Each bloc was spaced from the others by $1.0 \mathrm{~m}$. The analyses showed gains for the characters, measured by heritability $\left(\mathrm{h}_{\mathrm{a}}{ }^{2}\right)$. The $\mathrm{CVg} / \mathrm{CVe}$ ratio showed selection effectiveness for NDM, PH, NPP e GY. The largest genetic variability (CVg) was detected by NPP and GY. The correlations were of médium magnitude for NDM and PH, NDM and FPH, PH and FPH, PH and NPP, and NPP and GY. The paired correlation indicates selection for NDM leads to gain for FPH. Selection for NPP results in high GY. The graphic dispersion allows to observe genotypes one by one and indicates the the promising crosses to be advanced in the selection procedure.

Keywords: Biparental cross. Heritability. Correlation. CVg/CVe. Graphic dispersion.

\section{INTRODUÇÃO}

Os programas de melhoramento genético de soja têm desenvolvido cultivares com base nas demandas de mercado. $\mathrm{O}$ foco tem se concentrado na obtenção de cultivares mais produtivas, que expressem resistência a nematoides, doenças fungicas e insetos, estresse hídrico, salinidade, alumínio

\footnotetext{
${ }^{1}$ Universidade de Brasília
} 
(SPEHAR et al., 2014). Inclui-se ainda seleção por demanda especifica, como alto teor de óleo, proteínas ou com ausência de lipoxigenases resultando em melhor sabor (ANDRADE, 2012).

São escassas as informações sobre seleção em soja nas gerações iniciais após a hibridação. Isso ocorre pela dificuldade de realização dos cruzamentos, limitada quantidade de sementes colhidas nas plantas $F_{1}$, além do trabalho despendido com as avaliações. Testes em gerações iniciais $\left(F_{1}, F_{2}, F_{3}\right)$ possibilitam quantificar os efeitos sobre a expressão fenotípica dos caracteres e as estimativas de parâmetros genéticos importantes na seleção de genótipos, tais como, variância genética, herdabilidade e correlação entre caracteres (LOPES et al., 2002).

Logo, o conhecimento da variabilidade genética nos programas de melhoramento, permite a seleção de genitores que originam população com maior proporção de recombinantes desejáveis. Para os melhoristas, interessa a obtenção de variabilidade que efetivamente resulte em ganhos genéticos significativos (MUNIZ, 2007; VASCONCELOS et al., 2015).

A herdabilidade $\left(\mathrm{h}^{2}\right)$ é uma estimativa expressando a proporção da variância genética sobre a variância fenotípica. A herdabilidade é uma propriedade não somente do caráter de interesse, dependendo da magnitude de todos os componentes de variância, pois, alteração em qualquer um deles afetará o seu valor (BORÉM e MIRANDA, 2009). A estimativa de $\mathrm{h}^{2}$ é aplicada a uma dada população, sendo específica ao ambiente no qual os genótipos foram estudados. Adicionalmente, podem-se estimar herdabilidades diferentes para serem usadas em cálculos de predição, variando a unidade de seleção (OLIVEIRA et al., 2000). Valores altos de $\mathrm{h}^{2}$ indicam que métodos de seleção simples podem levar a ganhos consideráveis, considerando que o ambiente apresenta pouca influência (FALCONER, 1981).

A razão $\mathrm{CVg} / \mathrm{CV}$ e pode ser empregada como índice indicativo do grau de eficiência seletiva das progênies para cada caráter. Quando a razão $\mathrm{CVg} / \mathrm{CVe}$ for igual ou maior que a unidade, tem-se uma situação favorável à seleção, ou seja, a variação genética é a maior responsável pelas diferenças entre progênies (YOKOMIZO e FARIAS NETO, 2003).

A correlação pode ocorrer quando um gene interfere na expressão de outros. Se estiver segregando, causará variação simultânea nesses dois caracteres. Correlações positivas mostram, possivelmente, desequilíbrio de ligação gênica entre os pares, favorecendo a seleção simultânea de dois ou mais caracteres, com base em um destes. Em contrapartida, a seleção de um caráter pode acarretar seleção de alelo indesejável em outro gene. A correlação tem sido usada como estratégias para aumentar a eficiência do melhoramento genético, indicando a influencia que um caráter exerce sobre outro. Esse parâmetro explica o grau de associação entre duas variáveis, e, quando elas estão correlacionadas positivamente, existe uma covariação entre elas (RAMALHO, 2004).

Trabalhos para estimar a variabilidade genética e ambiental em soja têm sido explorados, com base em caracteres agronômicos em diferentes ambientes. Herdabilidade e correlações em plantas $\mathrm{F}_{2}$ de soja, triplo nula foram avaliadas em Minas Gerais (OLIVEIRA et al., 2000; LOPES et al., 2002). Correlações entre genótipos de soja cultivada sob condições de várzea irrigada, foram obtidas no cultivo em Tocantins (ALMEIDA et al., 2010). Matsuo et al. (2012) estimaram parâmetros genéticos na variação do hipocótilo e epicótilo da soja; estimativas de parâmetros genéticos e suas correlações foram obtidas a partir de genótipos de soja avaliados no Piauí (LEITE et al., 2015). Em São Paulo, Unêda-Trevisol et al. (2012) estimaram os parâmetros genéticos em linhagens precoces de soja.

A estimativa de parâmetros genéticos permite conhecer a estrutura genética de populações para fins de seleção. Este trabalho objetivou estimar parâmetros genéticos (herdabilidade, coeficiente de variação genética e razão da variação genética e ambiental $\mathrm{CVg} / \mathrm{CVe}$ ), calcular correlações fenotípicas

Nucleus,v.15,n.1,abr.2018 
entre caracteres agronômicos e variabilidade genética de populações $F_{2}$ de soja formadas por cruzamento biparentais e seus genitores visando aprimorar a seleção para altura de plantas, ciclo e produtividade.

\section{MATERIAL E MÉTODO}

O experimento foi conduzido na Fazenda Água Limpa, Universidade de Brasília (UnB) - DF, latitude $15^{\circ} 56^{\prime} \mathrm{S}$, longitude $47^{\circ} 56^{\prime} \mathrm{W}$ e altitude média de $1.080 \mathrm{~m}$. Segundo Koeppen, o clima é do tipo Aw tropical chuvoso de inverno seco. O solo é classificado como Latossolo Vermelho-Amarelo - LVA, textura argilosa, fase Cerrado. $\mathrm{O}$ solo da área foi analisado quimicamente para recomendação de calagem e adubação, para atender as exigências da cultura.

A semeadura foi realizada em 30 de dezembro de 2013. O delineamento experimental foi blocos casualizados com quatro repetições. Os tratamentos foram constituídos por 22 genótipos (Tabela 1). Cada parcela foi composta por uma linha com 2,5 m de comprimento com espaçamento de 1,0 m e 0,1 m entre plantas. Cada bloco foi espaçado dos demais por 1,0 m (modificado de SPEHAR, 1998).

Tabela 1: Genótipos de soja avaliados: Dez cultivares tradicionais de soja e doze genótipos de soja na geração $\mathrm{F}_{2}$ (oriundas de cruzamentos entre cultivares destinadas a alimentação humana com cultivares que apresentam período juvenil longo).

\begin{tabular}{|c|c|}
\hline $1-\mathrm{BRS} 257^{1}$ & 12-(BRS $257^{1}$ x CD 219) \\
\hline 2- CD 219 & 13-(BRS $257^{1}$ x M 8867) \\
\hline 3- DM 309 & 14- (BRS $257^{1}$ x M 9144) \\
\hline 4- M 8867 & 15-(BRS $257^{1} \times$ A 7002) \\
\hline 5- M 9144 & 16- (BRS $257^{1} \times$ Conquista) \\
\hline 6- M 7002 & 17-(UFVTN105¹ x M 9144) \\
\hline 7- Conquista & 18-(UFVTN105 x M 8867) \\
\hline 8- M 8585 & 19-(UFVTN105¹ x M 8585) \\
\hline 9- UFVTN $105^{1}$ & 20- (M $8585 \times$ BRS $\left.257^{1}\right)$ \\
\hline 10- BRS Amaralina & 21-(Amaralina $\mathrm{x}$ UFVTN $\left.105^{1}\right)$ \\
\hline 11- (BRS $257^{1}$ x DM 309) & 22- $\left(\right.$ Conquista $x$ UFVTN105 $\left.{ }^{1}\right)$ \\
\hline
\end{tabular}

Fonte: elaborado pelos autores deste artigo

${ }^{1}$ Cultivares destinados a alimentação humana, que apresentam características alimentares e ausência dos alelos dominantes que codificam as três enzimas de lipoxigenases.

Realizaram-se aração e gradagens antecedendo à semeadura, precedida por inoculação e tratamento das sementes com estirpes de Bradyrhizobium japonicum na dose de $500 \mathrm{~g}$ de inoculante para $50 \mathrm{~kg}$ e fungicida Carbendazim-Thiram $200 \mathrm{SC}$, na dose de $200 \mathrm{~mL} / 100 \mathrm{Kg}$. A adubação foi realizada com base na análise de solo e nas recomendações para a cultura, correspondendo a $500 \mathrm{~kg} \mathrm{ha}{ }^{-1} \mathrm{da}$ formulação NPK 00-16-16. O controle das plantas daninhas foi feito por meio de capina manual. Para controle da ferrugem asiática (Phakopsora pachrhizi) foram realizadas pulverizações 0,6 L.ha $^{-1}$ do fungicida Opera ${ }^{\circledR}$ (Piraclostrobina e Epoxiconazol) com intervalos de 20 dias a partir do estádio $\mathrm{R}_{1}$ (FEHR;CAVINESS, 1977) das plantas de soja. 
A colheita ocorreu a partir de abril de 2014, de acordo com a maturação (estádio $\mathrm{R}_{9}$ ). As plantas foram colhidas em conjunto de acordo com a maturação por parcela, posteriormente avaliadas, debulhadas e armazenadas individualmente.

As características agronômicas avaliadas foram: a) número de dias para maturação (NDM), período que correspondeu ao período desde a emergência das plântulas até a data em que $95 \%$ das vagens das plantas da parcela apresentaram-se maduras; b) altura das plantas (AP), realizada na maturação medindo da base da planta até a inserção do rácemo no ápice da haste principal; c) altura de inserção da primeira vagem (AIV), realizada na maturação medindo a distância, a partir da base da planta até a primeira vagem da haste principal; d) número de vagens por plantas (NVP), média obtida por contagem direta de vagens por planta; e) rendimento de grãos por planta (RG): determinado após a trilha das plantas e limpeza das sementes convertendo-os em $g$ planta $^{-1}$.

Foi realizada análise de variância com base na média das parcelas, visando avaliar a variabilidade genética entre genitores e cruzamentos. A estimativa dos componentes da variância foi realizada pelo programa Genes (CRUZ, 2006). Foram estimados: variância genotípica entre médias; variância ambiental; herdabilidade no sentido amplo; coeficiente de variação genética; correlações fenotípicas; razão $\mathrm{CVg} / \mathrm{CVe}$, onde valores maiores que 1,0 (um) possibilitam uma seleção efetiva por métodos mais simples de melhoramento e favorecem a seleção fenotípica de caracteres (PIMENTELGOMES, 1985; CRUZ et al., 2004).

Foram obtidos ainda coeficientes de correlação entre os caracteres onde: $r=0$ (nula); $0<|r| \leq$ 0,30 (fraca); $0,30<|\mathrm{r}| \leq 0,60$ (média); $0,60<|\mathrm{r}| \leq 0,90$ (forte); $0,90<|\mathrm{r}| \leq 1$ (fortíssima) e $|\mathrm{r}|=1$ (perfeita) (CARVALHO et al., 2004). Utilizaram-se gráficos cartesianos para demonstrar a diversidade genética, aplicando-se a análise de coordenadas principais (CRUZ et al., 2004).

\section{RESULTADO E DISCUSSÃO}

Verificou significância a $\mathrm{p}<0,01$ para todas as características avaliadas (Tabela 2). Esses resultados demostram a variabilidade entre os genótipos testados. O coeficiente de variação está de acordo com o relatado na literatura (LOPES et al., 2002; CARVALHO et al., 2009). Verificou amplitude, entre as médias máxima e mínima, de 68 dias para maturação, $54,6 \mathrm{~cm}$ na altura entre plantas, $9,5 \mathrm{~cm}$ na altura de primeira vagem, 130 vagens por planta e $30,17 \mathrm{~g}$ de grão por planta. Isso confirma a variabilidade encontrada.

Tabela 2. Resumo da análise de variância de 22 genótipos de soja de ensaio conduzido na Fazenda Água Limpa, UnB, Brasília, 2014.

\begin{tabular}{lllllll}
\hline \multirow{2}{*}{ FV } & & \multicolumn{5}{c}{ Quadrado médio } \\
\cline { 3 - 7 } & L & NDM & AP & AIV & NVP & RG \\
\hline Bloco & & 729,071 & 169,991 & 9,192 & 366,465 & 14,858 \\
Renótipo & 1 & $923,058^{* *}$ & $358,336^{* *}$ & $6,948^{* *}$ & $1398,941^{* *}$ & $54,773^{* *}$ \\
\hline CV(\%) & 3 & 37,341 & 23,711 & 2,174 & 214,153 & 10,060 \\
\hline Média & & 4,79 & 7,01 & 15,19 & 24,57 & 23,54 \\
Média max. & 127,5 & 69,44 & 9,70 & 59,56 & 13,47 \\
Média min. & 162 & 97,20 & 14,50 & 142,33 & 33,86 \\
& 94 & 42,60 & 5,00 & 12,00 & 3,69 \\
\hline
\end{tabular}

. Fonte: elaborado pelos autores deste artigo. $\quad * *$ significativos a $\mathrm{P}<0,01$ pelo teste $\mathrm{F}$

NDM: número de dias para a maturação; AP: altura das plantas; AIV: altura da inserção da primeira vagem; NVP: número de vagens por plantas e RG: rendimento de grãos por planta. 


\section{Herdabilidade}

O coeficiente de herdabilidade $\left(\mathrm{h}_{\mathrm{a}}{ }^{2}\right)$ reflete os valores de herança e do ambiente na expressão de caracteres. Assim quanto maior esse coeficiente, maior o sucesso da seleção para um dado caráter. Esse coeficiente pode variar de 0 a 1 , sendo valores maiores que 0,5 (alta herdabilidade); valores entre 0,2 e 0,5 (herdabilidade média) e menores que 0,2 (herdabilidade baixa) (SILVEIRA et al., 2006). Os valores de coeficientes de herdabilidade $\left(\mathrm{h}_{\mathrm{a}}{ }^{2}\right)$ encontram-se nas (Tabela 3$)$. O número de dias à maturação apresentou maior herdabilidade $\left(\mathrm{h}_{\mathrm{a}}{ }^{2}=0,95\right)$, seguido da altura de plantas $\left(\mathrm{h}_{\mathrm{a}}{ }^{2}=0,93\right)$, número de vagens por planta $\left(h_{a}{ }^{2}=0,84\right)$, rendimento de grãos $\left(h_{a}{ }^{2}=0,80\right)$ e altura de inserção de vagens $\left(h_{a}{ }^{2}=0,68\right)$. Os coeficientes superiores a 0,5 confirmaram alta herdabilidade para essas características com isso indicando serem facilmente fixáveis no avanço de geração (YOKOMIZO, 2012). Resultados semelhantes foram obtidos por na cultura da soja Leite et al. (2015).

Tabela 3. Estimativas das variâncias fenotípica $\left(V_{f}\right)$, genotípica $\left(V_{g}\right)$, ambiental $\left(V_{e}\right)$, herdabilidade sentido amplo $\left(\mathrm{h}_{\mathrm{a}}{ }^{2}\right)$, coeficiente de variação genético $\left(\mathrm{CV}_{\mathrm{g}}\right)$ e razão entre coeficiente de variação genética e ambiental $\left(\mathrm{CV}_{\mathrm{g}} / \mathrm{CV}_{\mathrm{e}}\right)$, para características agronômicas entre genótipos de soja. Fazenda Água Limpa, UnB, DF, Brasília, 2014.

\begin{tabular}{llllll}
\hline Variância Estimada & NDM & AP & AIV & NVP & RG \\
\hline $\mathrm{V}_{\mathrm{f}}$ (média) & 230,76 & 89,58 & 1,73 & 349,73 & 13,69 \\
$\mathrm{~V}_{\mathrm{e}}$ (média) & 9,33 & 5,92 & 0,54 & 53,53 & 2,51 \\
$\mathrm{~V}_{\mathrm{g}}$ (média) & 221,42 & 83,65 & 1,19 & 296,19 & 11,17 \\
$\mathrm{~h}_{\mathrm{a}}{ }^{2}$ (média) & 0,95 & 0,93 & 0,68 & 0,84 & 0,80 \\
$\mathrm{CV}_{\mathrm{g}}$ & 11,66 & 13,17 & 11,25 & 28,89 & 24,80 \\
$\mathrm{CV}_{\mathrm{g}} / \mathrm{CV}_{\mathrm{e}}$ & 2,43 & 1,87 & 0,74 & 1,17 & 1,05 \\
\hline
\end{tabular}

Fonte: elaborado pelos autores deste artigo.

NDM: número de dias para a maturação; AP: altura de planta; AIV: altura da primeira vagem; NVP: número de vagem por planta e RG: rendimento de grãos por planta.

Valores de herdabilidade médios a altos indicam que grande parte da variabilidade fenotípica possui causas genéticas, com menor efeito ambiental (UNÊDA-TREVISOLI, et al., 2012).

\section{Coeficiente de Variação Genético (CVg)}

O coeficiente de variação genético $(\mathrm{CVg})$ é um parâmetro importante que permite inferir sobre a magnitude da variabilidade genética presente na população para todos os caracteres em estudo (FERRÃO et al., 2008), tendo implicações diretas no ganho por seleção. No caso de seleção CVg dá ideia sobre a proporcionalidade do ganho em relação à média, enquanto a razão $\mathrm{CVg} / \mathrm{CVe}$ maior que a unidade $(>1)$, indica situação favorável à seleção (FALEIRO et al., 2002).

Os coeficientes de variação genética demonstraram a variabilidade genética existente na população para cada caráter (Tabela 3), com variação de 11,25 a $28,89 \%$ entre AIV e NVP, respectivamente. Os caráteres NVP e RG foram os que apresentaram maiores variabilidades $(\mathrm{CVg}=28,89$ e 24,80\%, respectivamente), enquanto os menores valores foram observados para AIV e AP. Resultados semelhantes de CVg para os caracteres de rendimento e os menores para ciclo, altura de plantas e de primeira vagem foram verificados em outros trabalho (COSTA et al., 2008). De acordo com Ubi et al. 
(2007) valores elevados são favoráveis à seleção, pois apresentam a possibilidade de maiores ganhos genéticos para o caractere.

\section{Razão CVg/CVe}

Essa razão foi maior que a unidade para todas variáveis respostas analisadas (Tabela 3), exceto altura de primeira vagem. Para NDM, AP, NVP e RG, os valores da razão CVg/CVe foram 2,43; 1,87; 1,17 e 1,05, respectivamente, estando em concordância com os maiores valores de herdabilidade. Estes valores sugerem boas perspectivas de ganho genético por seleção direta, uma vez que a variância genética superou a ambiental, ou seja, as características manifestaram-se devido a maior contribuição genética (YOKOMIZO, 2012).

A razão $\mathrm{CVg} / \mathrm{CVe}$ foi de 0,74 para altura de primeira vagem. Este valor sugere uma condição pouco favorável à seleção desse caráter, pois a maior contribuição existente foi de origem ambiental. Com o valor maior da variância ambiental do que genético indica que este caráter interage possivelmente de forma intensa com variações ambientais. Neste contexto, sugere-se que no processo de desenvolvimento de linhagens/cultivares de soja, que se utilize outra alternativa como, por exemplo a seleção indireta com auxilio dos coeficientes de correlação deste com outros como maturação e altura de plantas.

A seleção indireta é mais efetiva nessas condições devido à alta magnitude da herdabilidade para altura de plantas, e da correlação feita entre altura de plantas e altura de primeira vagem. A seleção indireta mostra-se eficaz, desde que seja realizada em ambientes responsivos, que maximizem a herdabilidade e correlação (CAIERÃO et al., 2006).

Os resultados obtidos para AIV estão de acordo Leite et al. (2015) que também verificaram coeficiente inferiores a 1 para altura de primeira vagem, enquanto os demais variáveis apresentaram valores superiores a unidade. Entretanto, Silveira et al. (2006) obtiveram valores inferiores a unidade para produtividade.

\section{Correlação}

Não foram observadas correlações significativas entre os caráteres avaliados (Tabela 4). Entretanto, os valores foram positivos com magnitude média segundo Carvalho et al. (2004) entre os caráteres NDM e AP, NDM e AIV, AP e AIV, AP e NVP, e NVP e RG. Pode-se inferir que o ciclo da cultura influenciou a altura da planta e a altura da primeira vagem. De modo similar, a altura da planta relacionou-se direta e positivamente com altura de vagem e número de vagens por plantas. E plantas com maior número de vagens também foram as mais produtivas confirmando a tendência encontrada por Almeida et al. (2010).

Tabela 4. Estimativas de valores de correlação fenotípica entre características agronômicas de 22 genótipos de soja. Fazenda Água Limpa. Brasília, 2014.

\begin{tabular}{llllll}
\hline & NDM & AP & AIV & NVP & RG \\
\hline NDM & 1 & 0,361 & 0,595 & $-0,129$ & 0,244 \\
AP & - & 1 & 0,438 & 0,355 & 0,252 \\
AIV & - & - & 1 & $-0,059$ & 0,078 \\
NVP & - & - & - & 1 & 0,500 \\
REND & - & - & - & - & 1 \\
\hline
\end{tabular}

Fonte: elaborado pelos autores deste artigo.

NDM: número de dias para a maturação; AP: altura de planta; AIV: altura da primeira vagem; NVP: número de vagem por planta e RG: rendimento de grãos por planta. 
De acordo com Falconer (1981) essa correlação entre os caracteres permite fazer seleção indireta e obter progresso mais rápido do que na seleção direta. Assim, a seleção realizada apenas número de dias à maturação, que apresentou altas estimativas de herdabilidade $\left(\mathrm{h}_{\mathrm{a}}{ }^{2}=0,95\right)$, favoreceria a seleção indireta na AIV. E selecionando o caractere $\operatorname{AP}\left(h_{\mathrm{a}}{ }^{2}=0,93\right)$ favoreceria a AIV que, a priori, indicou ser de mais difícil seleção, por apresentar valores inferiores de herdabilidade $\left(\mathrm{h}_{\mathrm{a}}{ }^{2}=0,68\right)$. Ao selecionar o caractere NVP $\left(\mathrm{h}_{\mathrm{a}}{ }^{2}=0,84\right)$ indiretamente seleciona plantas mais produtivas.

\section{Dispersão Gráfica}

$\mathrm{Na}$ análise visual da figura de componentes principais (Figura 1), pode-se observar que os genótipos apresentaram distribuição heterogênea para as duas primeiras variáveis (Altura de planta e número de dias maturação). Os genótipos mais divergentes foram 1 (BRS 257) e 10 (Amaralina). Os genótipos de maior proximidade foram 17,19 e 20 (UFVTN105 x M 9144, UFVTN105 x M 8585 e M 8585 x BRS 257). Neste grupo englobaram-se apenas progênies referentes aos respectivos cruzamentos; enquanto 4 e 6 (M 8867 e M 7002) e 2, 3 e 7 (CD 219, DM 309 e Conquista), formaram pequenos grupos com dois e três genitores.

As progênies $\mathrm{F}_{2}$ oriundas dos cruzamentos 21 (Amaralina x UFVTN105) e 22 (Conquista $\mathrm{x}$ UFVTN 105) apresentaram melhores desempenhos, tanto em relação a AP como no ciclo. Sendo, a priori, os mais promissores para obtenção de genótipos superiores com estas características. Entretanto, as progênies do cruzamento 15 (BRS 257 x A 7002) apresentaram altura superior a $70 \mathrm{~cm}$ e foram as mais precoces com maturação aos 107 dias. De forma generalizada, a distribuição das progênies dos cruzamentos (Tabela 2) foi heterogênea e concentraram-se com maturação entre 107 e 128 dias e a altura de plantas entre 58 a $87 \mathrm{~cm}$, respectivamente.

Figura 1. Dispersão gráfica de 22 genótipos de soja 1. BRS257, 2. CD 219, 3. DM 309, 4. M 8867, 5. M 9144, 6. M 7002, 7. Conquista, 8. M 8585, 9. UFVTN 105, 10. BRS Amaralina, 11. BRS 257 x DM 309, 12. BRS 257 x CD 219, 13. BRS 257 x M 8867, 14. BRS 257 x M 9144, 15. BRS 257 x A 7002, 16. BRS 257 x Conquista, 17. UFVTN105 x M 9144, 18. UFVTN105 x M 8867, 19. UFVTN105 x M 8585, 20. M 8585 x BRS 257, 21. Amaralina x UFVTN105 e 22. Conquista x UFVTN105, em relação aos dois primeiros componentes principais, estabelecidos pela combinação linear de cinco características agronômicas. Brasília, DF, 2014.

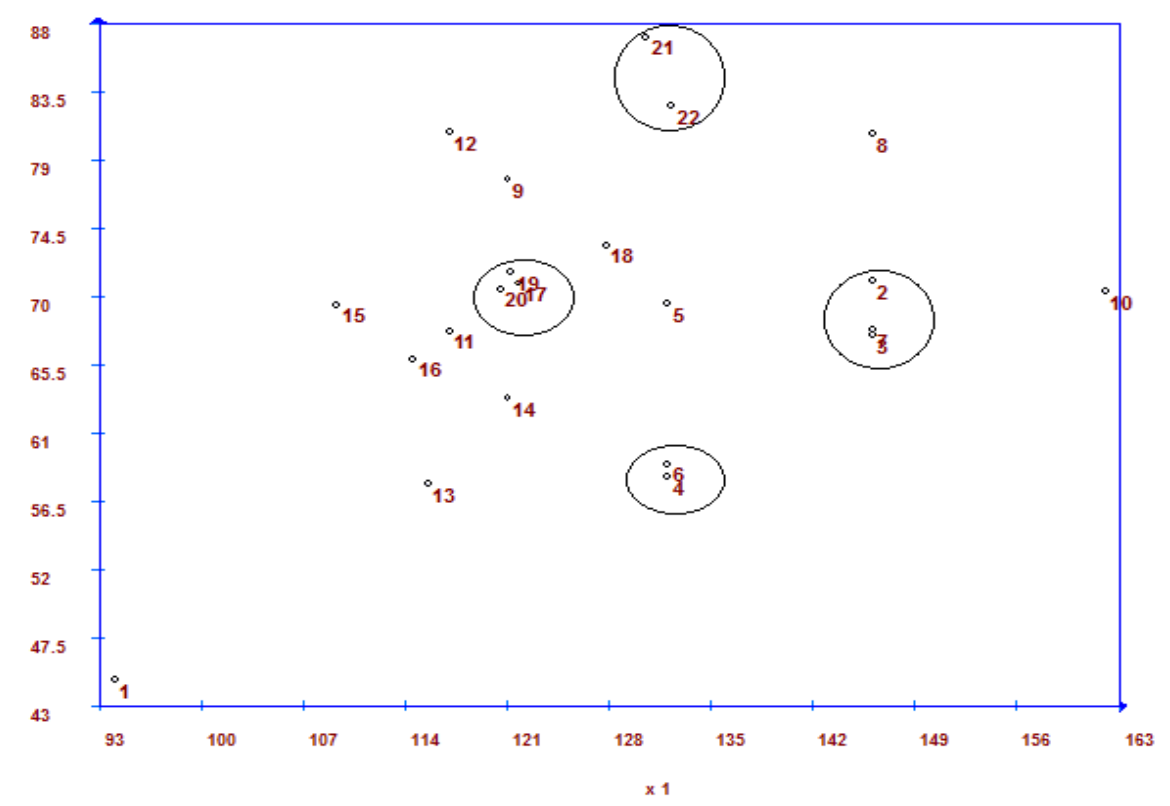

Fonte: elaborado pelos autores deste artigo 
A dispersão gráfica permitiu visualizar a dissimilaridade genética entre os genótipos. Logo, quanto mais distante sua distribuição gráfica, maior a dissimilaridade entre eles. Essa ferramenta foi usada com sucesso por Santos et al. (2011) e Cabral et al. (2011) em estudos com soja e feijão, respectivamente, para demostrar a dissimilaridade entre os genótipos testados.

A dissimilaridade encontrada refletiu variação genética, elevando a probabilidade de se encontrarem recombinantes desejáveis possuindo período juvenil longo e ausência de lipoxigenase. A continuação do trabalho com avanços de geração e seleção até atingir-se homozigose, permitiria obter genótipos de soja tipo alimento adaptada as baixas latitudes.

\section{CONCLUSÃO}

Existe elevada probabilidade de ganhos por seleção evidenciada pelos elevados valores de herdabilidade nas populações de híbridos de soja com período juvenil longo e ausência de lipoxigenase.

A seleção é favorável para número de dias à maturação, altura de plantas, número de vagens por planta e rendimento, com influência ambiental elevada dificultando a seleção por altura de inserção de vagem.

A maior variabilidade genética foi demonstrada por número de vagens por planta e rendimento de grãos.

Correlações positivas com magnitude média entre número de dias à maturação e altura de plantas, número de dias à maturação e altura de inserção de vagem, altura de plantas e altura de inserção de vagem e número de vagens por planta e rendimento permitem seleção indireta para obterem genótipos desejáveis.

A dispersão gráfica permitiu observar os genótipos de forma isolada, apontando os cruzamentos mais promissores para serem avançados.

\section{REFERÊNCIAS}

ALMEIDA, R. D.; PELUZIO, J. M.; AFFERI, F. S. Correlações fenotípicas, genotípicas e ambientais em soja cultivada sob condições de várzea irrigada, sul do Tocantins. Bioscience Journal, Uberlândia, v.26, n.1, p.95-99, 2010. <http://www.seer.ufu.br/index.php/biosciencejournal/article/viewFile/7044/4670>

\section{ANDRADE, V. Marcadores morfológicos e moleculares na identificação e distinção de off-type em campos de produção de sementes de soja. Dissertação Mestrado. 2012. 63 p .Universidade Federal de Uberlândia. Disponível em: \\ < https://repositorio.ufu.br/bitstream/123456789/12175/1/Vinicius\%20de\%20Andrade.pdf >}

BORÉM, A.; MIRANDA, G. V. Melhoramento de plantas. 5.ed. Viçosa: EDUFV, 2009. 529 p.

CABRAL, P. D. S.et al.Diversidade genética de acessos de feijão comum por caracteres agronômicos.

Revista Ciência Agronômica, Fortaleza, n. 42, p. 898-905, 2011.

<http://www.ccarevista.ufc.br/seer/index.php/ccarevista/article/view/1277/624>

CAIERÃO, E. V.; CARVALHO, F. I. F.; FLOSS, E. L. Seleção indireta para o incremento do rendimento de grãos em aveia. Ciência Rural, Santa Maria, v. 36, p. 1126- 1131, 2006.

<http://www.scielo.br/pdf/cr/v36n4/a13v36n4.pdf>

CARVALHO, A. D. F.; GERALDI, I. O.; SANTOS, V. S. Evaluation of $F_{2: 4}$ and $F_{4: 6}$ progenies of soybeans and perspectives of using early generation testing for grain yield. Bragantia, Campinas, v. 68, n. 4, p. 857-861, 2009. <http://www.scielo.br/pdf/brag/v68n4/v68n4a05.pdf>

Nucleus,v.15,n.1,abr.2018 
CARVALHO, F. I. F.; LORENCETTI, C.; BENIN, G. Estimativas e implicações da correlação no melhoramento vegetal. Pelotas: Ed. Universitária da UFPel, 2004. 142 p.

COSTA, M. M.et al. Heritability estimation in early generations of two-way crosses in soybean.

Bragantia, Campinas, n. 67, p. 101-108, 2008. 〈http://www.scielo.br/pdf/brag/v67n1/a12v67n1.pdf〉

CRUZ, C.D. Programa GENES: estatística experimental e matrizes. Viçosa: UFV, 2006. 285p.

CRUZ, C. D.; REGAZZI, A. J.; CARNEIRO, P. C. S. Modelos biométricos aplicados ao melhoramento genético. 3. ed. Viçosa: UFV, 480 p, 2004.

FALCONER, D. S. Introdução à genética quantitativa. Viçosa MG: UFV, 1981. 279 p.

FALEIRO, F. G.et al. Comparação de blocos casualizados e testemunhas intercalares na estimação de parâmetros genéticos em feijoeiro. Pesquisa Agropecuária Brasileira, Brasília, v. 37, n. 12, p. 1675$1680,2002$.

<https://www.alice.cnptia.embrapa.br/alice/bitstream/doc/108845/1/1675.pdf>

FEHR, W. R.; CAVINESS, C. E. Stages of soybean development. Iowa State University. 12p. 1977. (Special Report, 80)

FERRÃO, R. G.et al.Parâmetros genéticos em café conilon. Pesquisa Agropecuária Brasileira, Brasília, v. 43, n. 1, p.61-69, 2008. Disponível em: http://seer.sct.embrapa.br/index.php/pab/article/view/7961/4720

LEITE, W. S.et al. Estimativas de parâmetros genéticos e correlações entre caracteres agronômicos em genótipos de soja. Nativa, Sinop, v. 3, n. 4, p. 241-245, 2015.

<DOI: http://dx.doi.org/10.14583/2318-7670.v03n04a03>

LOPES, A. C. A.et al. Variabilidade e correlações entre caracteres em cruzamentos de soja. Scientia Agrícola, Piracicaba, v. 59, p. 341-348, 2002. http://www.scielo.br/pdf/sa/v59n2/8931.pdf

MATSUO, E.et al. Estimates of the genetic parameters, optimum sample size and conversion of quantitative data in multiple categories for soybean genotypes. Acta Scientiarum Agronomy, Maringá, v. 34, n. 3, p. 265-273, 2012. <Doi: 10.4025/actasciagron.v34i1.14015>

MUNIZ, F. R. S. Análise da variabilidade genética em populações segregantes de soja. Tese Doutorado. 2007. 94 p. Universidade Estadual Paulista, Jaboticabal.

OLIVEIRA, A. C. B.et al. Herdabilidade e correlações em plantas $\mathrm{F}_{2}$ de soja cultivadas em diferentes condições ambientais. Acta Scientiarum Agronomy, v. 22, p. 889- 893, 2000.

< http://periodicos.uem.br/ojs/index.php/ActaSciAgron/article/view/2834>

PIMENTEL-GOMES, F. Curso de estatística experimental. São Paulo: Esalq, 1985. 467 p.

RAMALHO, M. A. P. SANTOS, J. B., PINTO, C. A. B. P. Genética na agropecuária. 3 ed. rev., Lavras: UFLA, 2004. $472 \mathrm{p}$.

SANTOS, E. R.et al. Divergência entre genótipos de soja, cultivados em várzea irrigada. Revista Ceres, Viçosa, v. 58, n.6, p. 755-764, 2011. 〈http://www.scielo.br/pdf/rceres/v58n6/12.pdf〉

SILVEIRA, G. D.; MAURO, A. O. D.; CENTURION, M. A. P. C. Seleção de genótipos de soja para a região de Jaboticabal -SP, Ano agrícola 2003-2004. Científica, Jaboticabal, v. 34, n.1, p. 92-98, 2006. $<$ http://cientifica.org.br/index.php/cientifica/article/view/33/18>

SPEHAR, C. R., FRANCISCO, E. R.; PEREIRA, E. A. Yield stability of soybean cultivars in crop seasons and sowing dates at low latitude Brazilian Savannah Highlands. Journal of Agricultural Science, Cambridge, v. 153, p. 1059-1068, 2014. <http://dx. doi.org/10.1017/s0021859614000781>. 
SPEHAR, C. R. Comparison between hill and row plots methods on selection of soybeans for aluminium tolerance in a Brazilian savannah (Cerrado) acid soil. Pesquisa Agropecuária Brasileira, Brasília, v.33, n.6, p.899-904,1998.<http://seer.sct.embrapa.br/index.php/pab/article/view/4912/7042>

UBI, B. E.; MIGNOUNA, H.; OBIGBESAN, G. Segregation for seed wight, pod lenghts and days to flowering following a cowpea cross. African Crop Science Journal, Kampala, v. 9, n. 3, p. 463-470, 2007. <http://www.scielo.br/scielo.php?script=sci_nlinks\&ref=000143\&pid=S0034-

737X201200010001300027\&lng=en>

UNÊDA-TREVISOLI, S. H.et al. Estimativa de parâmetros genéticos em linhagens precoces de soja com aptidão para áreas de reforma de canavial. Ciência \& Tecnologia, Jaboticabal, v. 4, 2012.

<http://www.citec.fatecjab.edu.br/index.php/files/article/viewFile/81/pdf>

VASCONCELOS, E.et al. Produtividade de grãos, adaptabilidade e estabilidade de genótipos de soja de ciclos precoce e médio. Semina, Londrina, v. 36, n. 3, p. 1203-1214, 2015.

<DOI: $10.5433 / 1679-0359.2015 \mathrm{v} 36 \mathrm{n} 3 \mathrm{p} 1203>$

YOKOMIZO, G. K. Produtividade da soja na região do Município de Tartarugalzinho - AP.

Comunicado Técnico, Embrapa, p.1-5, 2012

http://ainfo.cnptia.embrapa.br/digital/bitstream/item/67305/1/AP-2012-Produtividade-soja-

Tartarugalzinho-CT-127.pdf

YOKOMIZO, G. K.; FARIAS NETO, J. T. Caracterização fenotípica e genotípica de progênies de pupunheira para palmito. Pesquisa Agropecuária Brasileira, Brasília, v. 38, n.1, p.67-72, 2003. http://seer.sct.embrapa.br/index.php/pab/article/view/6545/3602 